\title{
Estimation of mean movement rates for blue sharks in the northwestern Pacific Ocean
}

\author{
Mikihiko Kai* ${ }^{*}$ and Yuki Fujinami
}

\begin{abstract}
Background: The blue shark Prionace glauca is a highly migratory species with a circumglobal distribution. Mean movement rate, defined by the horizontal tracking distance between two data points over the duration of time, is commonly used to understand the horizontal displacement of highly migratory species across a wide range. However, the estimation of mean movement rates for blue sharks has never been conducted using a statistical model. We therefore investigated the mean movement rates using a generalized linear mixed model with data from satellite tags to estimate the range of mean movement rates for 10 blue sharks in the northwestern Pacific Ocean and to reveal the interaction of mean movement rate with several factors.

Results: (1) Estimations of mean movement rates for the 10 blue sharks were significantly influenced by behavioral differences among individuals; (2) uncertainty in the estimation (i.e., predictive and confidence intervals) of mean movement rates for these blue sharks was larger over shorter time periods, and (3) the predictive intervals of mean movement rates for the sharks ranged widely from 0.33 to $5.02 \mathrm{~km} / \mathrm{h}$.
\end{abstract}

Conclusion: Blue sharks are considered to opportunistically change their mean movement rates regardless of differences in sex, movement direction, or season.

Keywords: GLMM, Highly migratory shark, Movement rates, Satellite tagging, SPOT-tag

\section{Introduction}

The blue shark Prionace glauca is a highly migratory species inhabiting oceanic and circumglobal waters from temperate to tropical regions [1]. Understanding the horizontal movement patterns of animals is essential in the development of conservation and management measures, because such knowledge aids in clearly assessing their habitat use as well as their stock structure [2-6]. Satellite tags such as smart position only or temperature transmitting tags (SPOTs) and pop-up satellite archival tags (PSATs) are highly versatile location trackers commonly used to investigate the movement of highly migratory species such as tunas, billfishes, and sharks [e.g., 7-9]. The movement patterns of blue shark have been globally

\footnotetext{
*Correspondence: kaim@affrc.go.jp
}

Fisheries Resources Institute, Japan Fisheries Research and Education

Agency, 5-7-1 Orido, Shimizu-ku, Shizuoka, Shizuoka 424-8633, Japan investigated using these tags [e.g., 10, 11], however such information from the western and central North Pacific Ocean is still lacking [7].

Mean swimming speed (MSS) is one of the vital parameters for understanding the behavior ecology of pelagic sharks [12]. The values for blue shark had been estimated globally using ultrasonic acoustic telemetry, and the resulting observed range was from 1.3 to $3.7 \mathrm{~km} / \mathrm{h}$ [13-15]. The data-loggers with biologging sensors (e.g., speed, acceleration, and depth/temperature) enable us to observe swimming behavior in three dimensions and to record the actual swimming speed, even though the records are limited to a narrow area and a short tracking duration [13-15]. The past results suggested that MSS was highly variable depending on the behavioral differences among individual sharks, prey and predator interaction, water current, and time of day [13-15]. On the other hand, the mean movement rate (MMR), defined by 
the horizontal tracking distance between two data points over the duration of time, is frequently calculated using the data of satellite tags [e.g., 16]. MSS is a speed relative to water, whereas MMR is a speed relative to ground. MMR is also expected to be strongly influenced by various factors such as water currents and behavioral differences among individual sharks. The advantage of satellite tags is that they allow us to collect the point-to-point rate of movement across a wide area over a long tracking duration, while it is impossible to calculate the actual MSS in consideration of active vertical behavior and co-existing high site fidelity. The MMR is also used for estimating light-based geolocations of highly migratory species (https://wildlifecomputers.com/blog/using-gpe3to-improve-geolocation-estimates/). The estimation of MMR for blue shark, however, has never been conducted using a statistical model, and the interaction of MMR with various factors such as behavioral differences among individuals, sex, movement direction, and seasons is not clearly known.

In this study, we focus on the estimation of MMR for blue sharks in the northwestern Pacific Ocean using satellite tracking data obtained from SPOTs, and then we examine the uncertainties in the estimation of the MMR and the interaction of MMR with the various factors using a generalized linear mixed model (GLMM) with fixed and random effects.

\section{Methods}

In May 2019, we attached 12 SPOTs (SPOT-196; Wildlife Computers Inc., Redmond, WA, USA) on blue sharks in the northwestern Pacific Ocean $\left(38-39^{\circ} \mathrm{N}, 146-147^{\circ}\right.$ E) using a chartered Japanese commercial vessel (No. 37 Den-Maru). Live blue sharks (exhibiting active, strong or responsive movements) captured by longline gear were brought on board for tagging. During the tagging procedures, sharks were ventilated using a saltwater irrigation hose, and their eyes were covered with a black damp cloth to reduce stress. Sex was visually determined by the presence or absence of male claspers. Dorsal length (DL, to the nearest $\mathrm{cm}$ ) was measured as the straight distance from the first-dorsal-fin origin to the second-dorsal-fin origin. For the data analysis, DL was converted to precaudal length (PCL, the distance to the tip of the precaudal pit) using a conversion equation [17]. The SPOTs were fixed to the first dorsal fin using three nylon bolts and locknuts through holes that were drilled. The SPOTs were programmed to always transmit signals to Argos satellites when the dorsal fin broke the sea surface. The Argos satellite system categorizes location accuracy into seven classes from high to low quality. The set-by-set data used in this analysis includes ID number, quality of location accuracy, sex, PCL, recorded date, time, and location.

Commonly used data filtering was conducted to remove accuracy estimations of lower quality (i.e., no accuracy estimation, invalid location, or estimation errors larger than $1500 \mathrm{~m}$ ) from SPOTs to improve the quality of the location data. Subsequent standard statistical data filtering was conducted using the interquartile rule, which determines whether the point is higher or lower than the 1.5 interquartile range, to remove outliers in the data and avoid under- and over-estimation of MMRs. The MMR between two locations for an individual shark was calculated using the data on location and elapsed time transmitted from the SPOT via the Argos system. The tracking distances and direction of movement between two locations (i.e., locations of two consecutive data regarding the recorded time after data was filtered) were calculated using the 'geosphere' package [18] in software R 3.6 [19].

MMR was estimated through a modeling of the relationships between the tracking distances of two locations and the elapsed times to avoid the adverse effects of division, such as losing information on observation errors, when distance was divided by time. Several factors such as sex, movement direction, season, and behavioral differences among individuals were added to the model to investigate the effects on the response variable. To handle repeated observations from the same individuals, we used the GLMM:

$$
\lambda_{s, d, q, r, h}=e^{s+d+q+\delta(r)+\log (\mathrm{h})},
$$

where $\lambda_{s, d, q, r, h}$ represents the mean tracking distance for $\operatorname{sex} s$ (where $s=1$ and $s=2$ signify male and female), movement direction $d$ (where $-135 \leq d<-45,-45 \leq d<45$, $45 \leq d<135$, and $135 \leq d<180$ and $-180 \leq d<-135$ signify eastward, northward, westward, and southward directions), season $q$ (where $q=1,2,3$, and 4 signify Jan-Mar, Apr-Jun, Jul-Sep, and Oct-Dec), individual shark $r$, and the time intervals of transmission between two locations $h$. The variation of individual shark $\delta(r)$ was treated as a random effect, and the other explanatory variables were treated as fixed effects.

Expected distance $\lambda_{i}$ for the $i$ th observation was compared with the observed distance $D_{i}(\mathrm{~km})$. Since $D$ is a continuous positive value, we assumed that the $\lambda$ s follow a gamma distribution with a log-link function. The estimation was conducted using the 'Ime4' package [20] in software R-3.6. The best model was selected based on the Akaike Information Criterion (AIC) [21] and Bayesian Information Criterion (BIC) [22]. The selected model was diagnosed using standard regression diagnostic statistics. 
A quantile-quantile (QQ) plot was used to visually assess the goodness of fits (i.e., normality). The percentage of deviance explained (\%DE) by model was used to measure the proportion of goodness of fits to the data that the model accounts for. The equation is

$$
\% D E=100 \times\left(1-\text { residual deviance } \times \text { null deviance }{ }^{-1}\right),
$$

where residual deviance is the difference in deviance between the saturated model (which has as many parameters as data values) and the analyzed model, and null deviance is the difference in deviance between the saturated model and the null model that includes only the intercept. To quantify uncertainties in the estimates, 95\% confidence intervals (95\% CI) were estimated using a bootstrapping method with 1000 iterations, and 95\% predictive intervals $(95 \% \mathrm{PI})$ were calculated from the parameter estimates of gamma distribution.

\section{Results}

Information on tagging data such as tag deployments and track durations is summarized in Table 1 . The data were collected from 10 blue sharks ( 7 males and 3 females). The track durations for all sharks were between 24 and 243 days with travel distances of 1013-7578 km. The horizontal movement of tracked blue sharks covered a large portion of the northwestern Pacific Ocean (Fig. 1). Four sharks (Sharks 1, 3, 7, and 8) migrated southwestward from temperate $\left(30-40^{\circ} \mathrm{N}\right)$ to sub-tropical waters $\left(10-30^{\circ}\right.$ N) (Fig. 1), and the other sharks (Sharks 2, 4-6, 9, and 10) stayed in temperate waters $\left(30-50^{\circ} \mathrm{N}\right)$, moving in eastwest directions (Fig. 1). The mean observed MMRs \pm SD for all sharks was $1.64 \pm 0.91 \mathrm{~km} \mathrm{~h}^{-1}, n=796$.

Two stages of data filtering reduced the number of datasets from 6142 to 878 after the first stage and to 796 after the second stage. The simpler model (Model 3) was selected by AIC and BIC as the most parsimonious model (Table 2). These results suggested that there was no significant relationship between the MMR of each shark and multiple effects such as season, sex, and movement direction. The QQ-plot showed a good fit of the residuals to the expected normal values (see inset in Fig. 2) and the \%DE by GLMM was approximately $89 \%$ (Table 2 ). These results suggested that the selected model (Model 3) fully accounted for the goodness of fits to the data. The observed tracking distance and MMR against the elapsed time were mainly concentrated in the shorter time periods (Figs. 2 and 3). The MMRs varied widely, and the 95\% PIs of the MMRs were wider along the y-axis, especially over the shorter time periods (Fig. 3). The mean \pm SD of the lower and upper bounds of the 95\% PI was $0.48 \pm 0.15 \mathrm{~km} / \mathrm{h}$ and $3.85 \pm 1.17 \mathrm{~km} / \mathrm{h}, n=796$, respectively. The estimated tracking distances from the best model were proportional to the time interval of transmission (Fig. 2), while the MMRs were inversely proportional to the time interval of transmission (Fig. 3). The estimated $\mathrm{MMR} \pm \mathrm{SD}$ for all sharks was $1.64 \pm 0.37 \mathrm{~km} / \mathrm{h}, n=796$. The $95 \%$ CI of the estimated tracking distance became wider as the elapsed time increased (Fig. 2), whereas that of the estimated MMR was almost constant throughout the elapsed time (Fig. 3). The mean \pm SD of the lower and upper bounds of the $95 \%$ CI was $1.42 \pm 0.38 \mathrm{~km} / \mathrm{h}$ and $2.15 \pm 0.73 \mathrm{~km} / \mathrm{h}, n=796$, respectively. Additionally, the estimated MMR varied considerably among individual sharks (Table 1).

\section{Discussion}

Our results suggested that (1) the estimations of MMR for blue sharks were significantly influenced by behavioral differences among individuals; (2) the uncertainty in the estimation (i.e., the $95 \% \mathrm{CI}$ and the $95 \% \mathrm{PI}$ ) of MMR was larger over the shorter time periods; (3) the $95 \%$ PIs of MMRs for blue sharks were wide $(0.33-5.02 \mathrm{~km} / \mathrm{h}$, $n=796$ ); and (4) blue sharks opportunistically changed their MMRs regardless of differences in sex, movement direction, or season.

Although only data from 7 male and 3 female blue sharks were used in this analysis, the effects of sex (i.e., the two levels of male and female) were included in the model because we had a total number of 796 tracking data comprising repeated measurement data for 10 individuals, 535 for the males and 261 for the females, which were quantities that merited their inclusion. The model diagnostics such as \%DE (approximately $89 \%$ ) and the QQ-plot indicated that the number of samples was sufficient to examine the effects of explanatory variables including sex on the estimation of MMR.

As mentioned above, the estimated MMRs for 10 sharks (i.e., $1.64 \mathrm{~km} / \mathrm{h}$ ) do not accurately reflect the actual MSSs between two locations. Site fidelity in a limited area, oscillatory diving behaviors, and zigzag swimming may cause an underestimation of MMRs compared to the actual MSSs. Watanabe et al. [12], for example, pointed out that horizontal MMR can be an underestimation in the water column, because fishes generally move vertically as well. These facts suggest that there is a high possibility that the MMR estimated from wide ranges of elapsed time was underestimated compared to the actual MSS. It is therefore inappropriate to determine an actual swimming speed of blue shark from our analysis, but the predicted value can provide the horizontal displacement of blue shark over a long tracking duration in a wide area such as the entire northwestern Pacific Ocean (Fig. 1). This information may be useful in understanding the migration behavior of blue sharks in relation to their biology and ecology. Our results including predictive and 


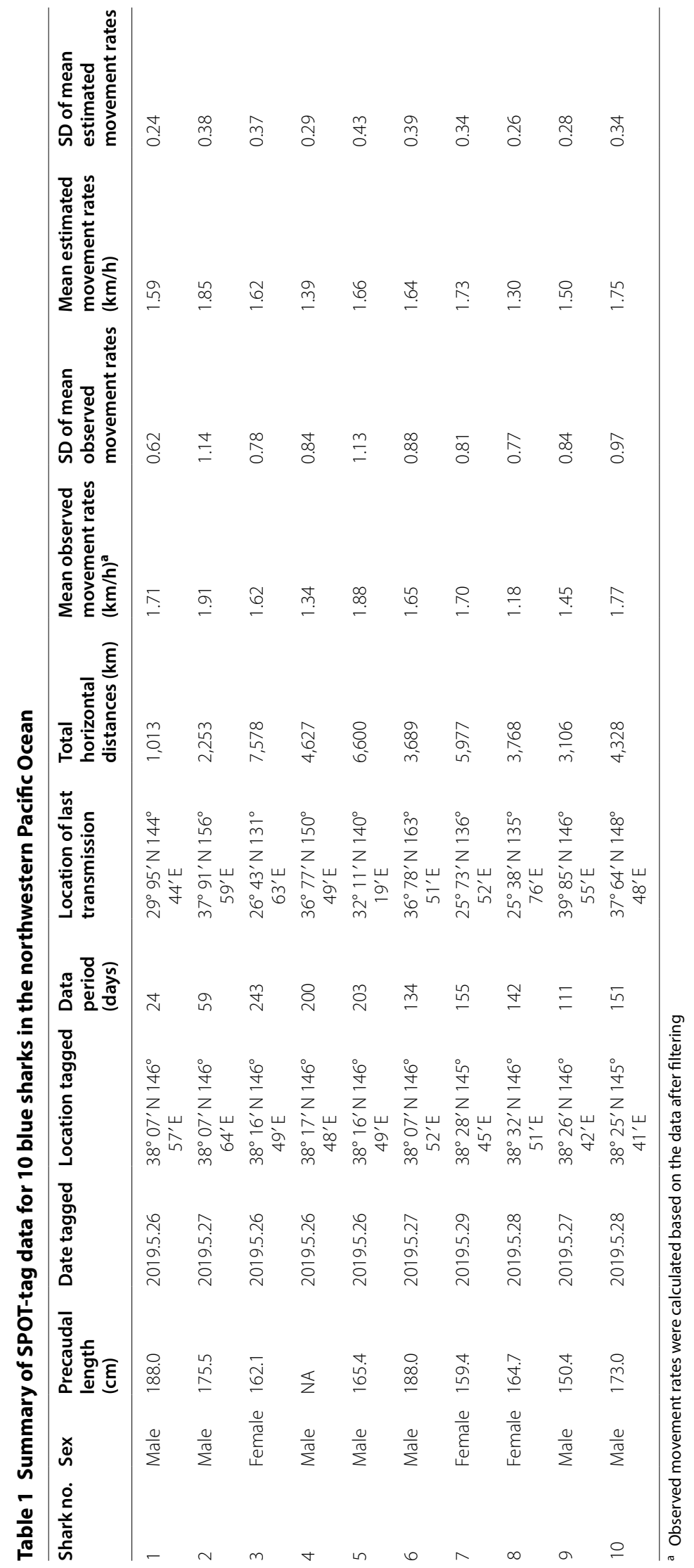




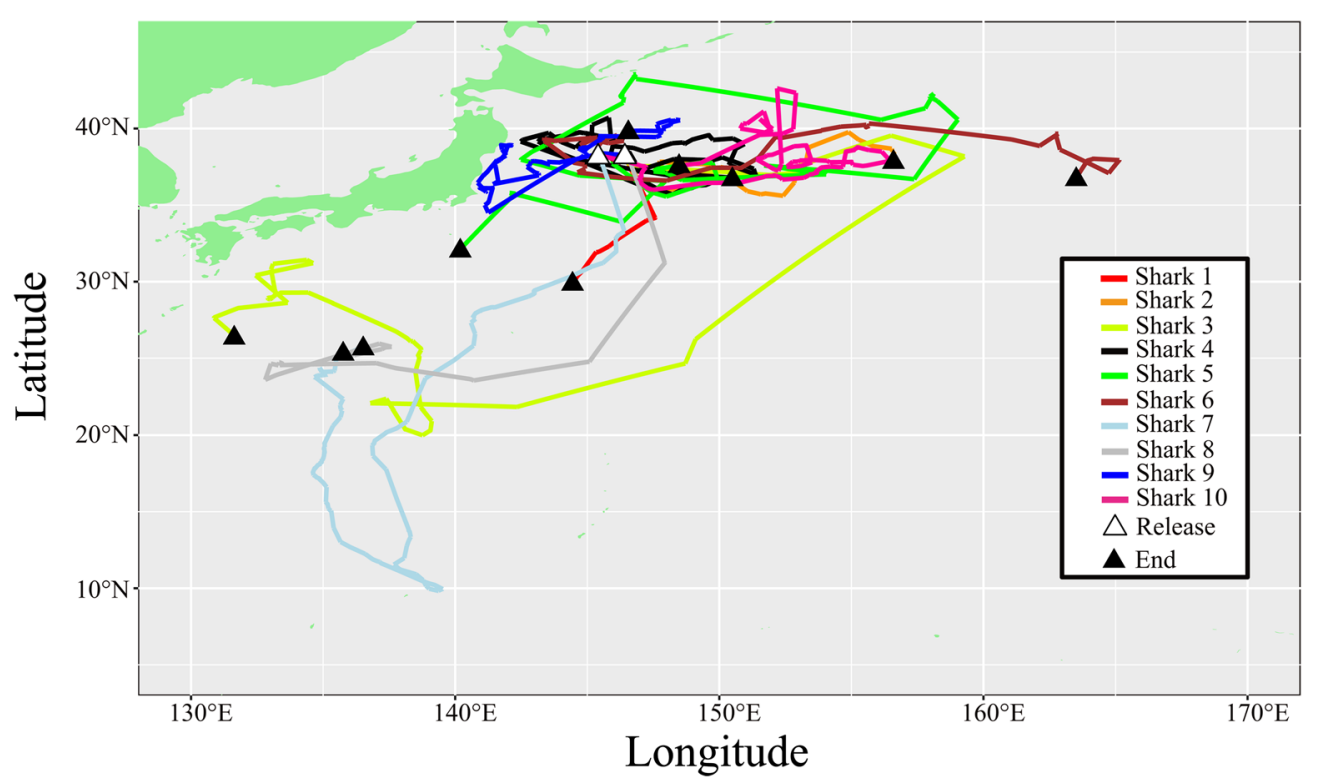

Fig. 1 Migration pathways of 10 blue sharks tracked from SPOT tags in the northwestern Pacific Ocean. Open triangles denote locations of sharks released with a tag, and solid triangles denote locations of last transmission from SPOT tags

Table 2 Summary of model selection information with 10 blue sharks in the northwestern Pacific Ocean

\begin{tabular}{|c|c|c|c|c|c|}
\hline Model & Linear predictor & DF & $\Delta \mathrm{AIC}$ & $\Delta \mathrm{BIC}$ & Convergence \\
\hline 0 & Null & 795 & 1984 & 1974 & Yes \\
\hline 1 & $\log$ (hours) & 794 & 10 & 5 & Yes \\
\hline 2 & Random (ID) & 793 & 1883 & 1878 & Yes \\
\hline 3 & Random (ID) + log(hours) & 792 & 0 & 0 & Yes \\
\hline 4 & Random (ID) + log(hours) + as.factor (sex) & 791 & 2 & 7 & Yes \\
\hline 5 & Random (ID) + log(hours) + as.factor (movement direction) & 789 & 0 & 14 & Yes \\
\hline 6 & Random (ID) + log(hours) + as.factor (season) & 789 & 1 & 15 & Yes \\
\hline 7 & Random (ID) + log(hours) + as.factor (season) + as.factor (movement direction) & 786 & 2 & 30 & No \\
\hline 8 & Random (ID) + log(hours) + as.factor (sex) + as.factor (season) & 788 & 3 & 21 & Yes \\
\hline 9 & Random (ID) $+\log ($ hours $)+$ as.factor (sex) + as.factor(movement direction) & 788 & 2 & 21 & Yes \\
\hline 10 & $\begin{array}{l}\text { Random (ID) + log(hours) + as.factor (sex) + as.factor (movement direction) + as. } \\
\text { factor (season) }\end{array}$ & 785 & 4 & 36 & No \\
\hline
\end{tabular}

$D F$ degree of freedom, \%DE percentage of deviance explained, $\triangle A I C$ and $\triangle B I C$ the reduction in AIC and BIC from the best-fitting model; log (hours) logarithmic elapsed time in hours between two locations, ID random effects of behavioral differences among individuals. The selected model is Model 3

confidence intervals also clearly demonstrated that the estimated MMR over shorter time periods tended to be faster than over longer time periods (Fig. 3). Burst movements due to prey and predator behavior, or transient directed movements over shorter time periods such as seasonal migrations for parturition, might contribute to an increase in the MMR.

A recent study based on satellite electronic tags for juvenile silky sharks Carcharhinus falciformis in the South Pacific Ocean [23] revealed a faster MMR (7.0$11.0 \mathrm{~km} / \mathrm{h})$. Meanwhile, other pelagic sharks such as whale sharks Rhincodon typus with satellite tags [24] showed slower MMR $(1.9 \mathrm{~km} / \mathrm{h})$. Another study on the MMR of shortfin mako Isurus oxyrinchus in the eastern Pacific Ocean [25] indicated that there was a significant difference between small sharks $(0.97 \mathrm{~km} / \mathrm{h})$ and large sharks $(1.33 \mathrm{~km} / \mathrm{h})$. The large differences among species may be caused by a rough calculation of MMR that does not consider behavioral differences among individuals and elapsed time. These results may fully support the wide ranges of MMR for blue shark. However, the extremely faster MMR for blue and silky shark may 


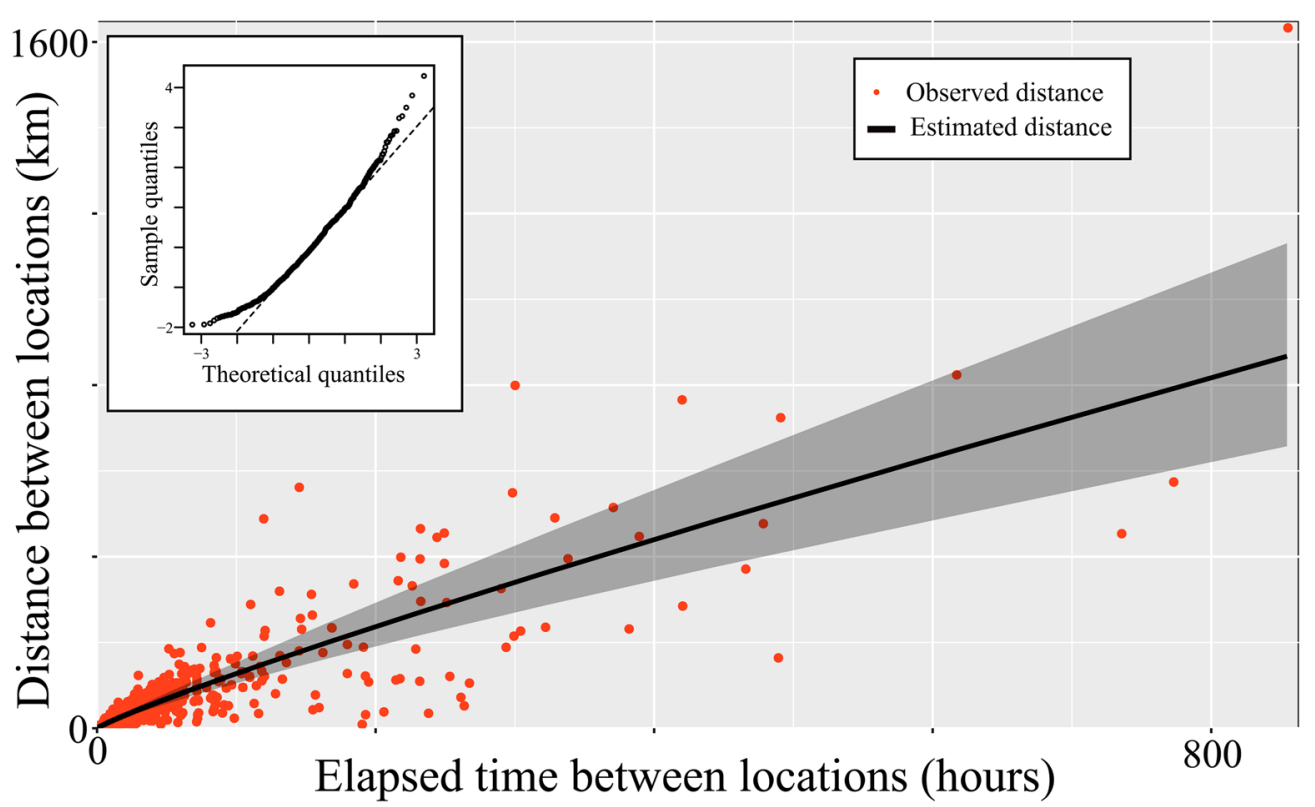

Fig. 2 Tracking distance $(\mathrm{km}$ ) between two locations (red points) of blue shark against time interval of transmission (hours). The curve represents the estimated tracking distance against the time interval. Shadow denotes the 95\% confidence intervals of the estimated curve. The inset shows the QQ-plot used to check the fit of the model to the data

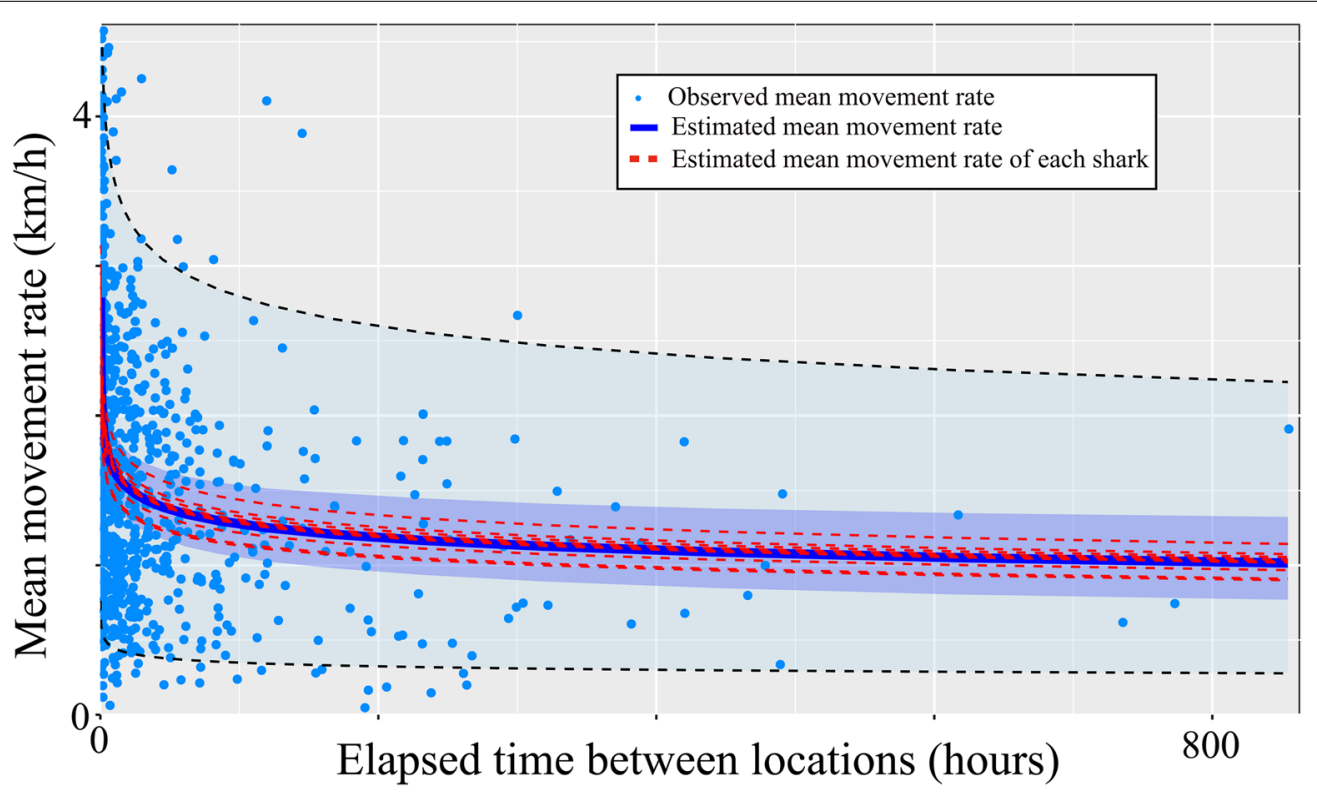

Fig. 3 Mean movement rate $(\mathrm{km} / \mathrm{h}$ ) of blue shark (blue points) against time interval of transmission (hours). The blue curve represents the estimated mean movement rate against the time interval. Blue shadow denotes the $95 \%$ confidence intervals of the estimated curve. Red dotted curves denote the estimated mean movement rate of individual sharks. Broken black lines with light blue shadow denote upper and lower $95 \%$ prediction lines

not support the linear relationship between MSS and the maximum annual migration range for ectothermic fishes
[12]. The extremely faster MMR during long periods of elapsed time may therefore be unrealistic for blue shark. 
Blue sharks are well known to exhibit spatial segregation by sex and ontogenetic stages in addition to the seasonal migrations [26, 27]. These ecological characteristics could change the relationships between elapsed time and tracking distance through changes in the duration of residence and migration. Our results for blue shark, however, could not find clear effects of season, sex, and movement direction on the estimation of MMRs. Accumulations of long-term tracking data with SPOT tags for different life-history stages of blue shark in the entire north Pacific Ocean will be necessary in future work to clarify the relationships between MMRs and the ecological characteristics of this species.

\section{Acknowledgements}

The authors sincerely thank Editor K. Sato and two anonymous reviewers who provided invaluable comments. We also thank all the crew of the chartered Japanese commercial vessel (No. 37 Den-Maru) for their support in shark tagging. We especially appreciate the contributions of Y. Semba and D. Ochi who assisted in the arrangements for the research cruise and necessary equipment.

\section{Authors' contributions}

MK developed the research idea and analyzed the data, and YF conducted tagging research, collected data and provided summarized data. MK and YF wrote the manuscript. Both authors read and approved the final manuscript.

\section{Funding}

This work was supported in part by a grant-in-aid from the Japan Fisheries Agency.

\section{Availability of data and materials}

All data generated or analyzed during this study are available from the corresponding author on reasonable request.

\section{Ethics approval and consent to participate}

Tagging procedures for this publication were carried out with prior permission from the Japan Fishery Agency and were approved by the Animal Experiment Committee at the Fisheries Resources Institute, Japan Fisheries Research and Education Agency (Approved experiment number: 45).

\section{Consent for publication}

Not applicable.

\section{Competing interests}

The authors declare that they have no conflicts of interest.

Received: 8 October 2020 Accepted: 25 November 2020

Published online: 03 December 2020

\section{References}

1. Nakano H, Stevens JD. The biology and ecology of the blue shark, Prionace glauca. In: Camhi MD, Pikitch EK, Babcool EA, editors. Sharks of the open ocean: biology, fisheries and conservation. Oxford: Blackwell Scientific; 2008. p. 140-51.

2. Block BA, Jonsen ID, Jorgensen SJ, Winship AJ, Shaffer SA, Bograd SJ, Hazen EL, Foley DG, Breed GA, Harrison AL, Ganong JE, Swithenbank A, Castleton M, Dewar H, Mate BR, Shillinger GL, Schaefer KM, Benson SR, Weise MJ, Henry RW, Costa DP. Tracking apex marine predator movements in a dynamic ocean. Nature. 2011;475:86-90. https://doi. org/10.1038/nature10082.

3. Berumen ML, Braun CD, Cochran JE, Skomal GB, Thorrold SR. Movement patterns of juvenilewhale sharks tagged at an aggregation site in the Red Sea. PLoS ONE. 2014;9:e103536. https://doi.org/10.1371/journ al.pone.0103536.
4. Frisk MG, Jordaan A, Miller TJ. Moving beyond the current paradigm in marine population connectivity: are adults the missing link? Fish Fish. 2014;15:242-54. https://doi.org/10.1111/faf.12014.

5. Bass NC, Mourier J, Knott NA, Day J, Brown C, Guttridge T. Long-term migration patterns and bisexual philopatry in a benthic shark species. Mar Freshw Res. 2017;68:1414-21.

6. Harrison AL, Costa DP, Winship AJ, Benson SR, Bograd SJ, Antolos M, Carliske AB, Dewar H, Dutton PH, Jorgensen SJ, Kohin S, Mate BR, Robinson PW, Schaefer KM, Shaffer SA, Shillinger GL, Simmons SE, Weng KC, Gjerde KM, Block BA. The political biogeography of migratory marine predators. Nat Ecol Evol. 2018;2:1571-8.

7. Sippel T, Holdsworth J, Dennis T, Montgomery J. Investigating behaviour and population dynamics of striped marlin (Kajikia audax) from the Southwest Pacific Ocean with satellite tags. PLoS ONE. 2011;6:e21087. https://doi.org/10.1371/journal.pone.0021087.

8. Teo SLH, Boustany A, Blackwell S, Walli A, Weng KC, Block BA. Validation of geolocation estimates based on light level and sea surface temperature from electronic tags. Mar Ecol Prog Ser. 2004;283:81-98. https://doi. org/10.3354/meps283081.

9. Queiroz N, Humphries NE, Couto A, Vedor M, Costa I, Sequeira AMM, et al. Global spatial risk assessment of sharks under the footprintof fisheries. Nature. 2019;572:461-6. https://doi.org/10.1038/s41586-019-1444-4.

10. Campana SE, Dorey A, Fowler M, Joyce W, Wang Z, Wright D, Yashayaev I. Migration pathways, behavioural thermoregulation and overwintering grounds of blue sharks in the Northwest Atlantic. PLoS ONE. 2011;6:e16854. https://doi.org/10.1371/journal.pone.0016854.

11. Vandeperre F, Aires-da-Silva A, Fontes J, Santos M, Serrão Santos R, Afonso P. Movements of blue sharks (Prionace glauca) across their life history. PLoS ONE. 2014;9:e103538. https://doi.org/10.1371/journal.pone.01035 38.

12. Watanabe Y, Goldman KJ, Caselle JE, Chapman DD, Papastamatiou YP. Comparative analyses of animal-tracking data reveal ecological significance of endothermy in fishes. Proc Natl Acad Sci. 2015;112:6104-9. https ://doi.org/10.1073/pnas.1500316112.

13. Carey FG, Scharold JV, Kalmijn AJ. Movements of blue sharks (Prionace glauca) in depth and course. Mar Biol. 1990;106:329-42. https://doi. org/10.1007/BF01344309.

14. Klimley AP, Beavers SC, Curtis TH, Jorgensen SJ. Movements and swimming behaviour of three species of sharks in La Jolla Canyon California. Environ Biol Fishes. 2002;63:117-35.

15. Sciarrotta TC, Nelson DR. Diel behaviour of the blue shark, Prionace glauca, near Santa Catalina Island California. Fish Bull. 1977;75:519-28.

16. Stevens JD, Bradford RW, West GJ. Satellite tagging of blue sharks (Prionace glauca) and other pelagic sharks off eastern Australia: depth behavior, temperature experience and movements. Mar Biol. 2010;157:575-91. https://doi.org/10.1007/s00227-009-1343-6.

17. Fujinami Y, Semba Y, Okamoto H, Ohshimo S, Tanaka S. Reproductive biology of the blue shark (Prionace glauca) in the western North Pacific Ocean. Mar Freshw Res. 2017;68:2018-27. https://doi.org/10.1071/MF161 01.

18. Hijmans RJ, Williams E, Vennes C. R-Package 'geosphere'. 2019. https:// cran.r-project.org/web/packages/geosphere/geosphere.pdf. Accessed 6 Nov 2020.

19. R Development Core Team. R: a Language and Environment for Statistical Computing. R Foundation for Statistical Computing, Vienna, Austria. 2017. http://www.R-project.org. Accessed 5 Nov 2020.

20. Bates D, Maechler M, Bolker B, Walker S, Christensen RHB, Singmann H, Dai B, Schepl, F, Grothendieck G, Green P, Fox J, Bauer A, Krivitsky PN. R-Package 'Ime4'. 2020. https://cran.r-project.org/web/packages/Ime4/ Ime4.pdf. Accessed 6 Nov 2020.

21. Akaike H. Information theory and an extension of the maximum likelihood principle. In BN Petrov, F Csaki, Editors. Proceedings of the Second International Symposium on Information Theory. Budapest: Akademiai Kiado; 1973. P. 267- 281

22. Schwarz GE. Estimating the dimension of a model. Ann Stat. 1978;6:4614. https://doi.org/10.1214/aos/1176344136.

23. Hutchinson M, Coffey DM, Holland K, Itano D, Leroy B, Kohin S, et al. Movements and habitat use of juvenile silky sharks in the Pacific Ocean inform conservation strategies. Fish Res. 2019;210:131-42. https://doi. org/10.1016/j.fishres.2018.10.016. 
24. Hueter RE, Tyminski JP, de la Parra R. Horizontal movements, migration patterns, and population structure of whale sharks in the Gulf of Mexico and northwestern Caribbean Sea. PLoS ONE. 2013;8:e71883. https://doi. org/10.1371/journal.pone.0071883.

25. Nasby-Lucas N, Dewar H, Sosa-Nishizaki O, Wilson C, Hyde JR, Vetter RD, Wraith J, Block BA, Kinney MJ, Sippel T, Holts DB, Kohin S. Movements of electronically tagged shortfin mako sharks (Isurus oxyrinchus) in the eastern North Pacific Ocean. Anim Biotelemetry. 2019;7:12. https://doi. org/10.1186/s40317-019-0174-6.

26. Nakano H, Seki MP. Synopsis of biological data on blue shark, Prionace glauca Linnaeus. Bull Fish Res Agen. 2003;6:18-55.
27. Kai M, Thorson JT, Piner KR, Maunder MN. Predicting the spatio-temporal distributions of pelagic sharks in the western and central North Pacific. Fish Oceanogr. 2017;26:569-82. https://doi.org/10.1111/fog.12217.

\section{Publisher's Note}

Springer Nature remains neutral with regard to jurisdictional claims in published maps and institutional affiliations.
Ready to submit your research? Choose BMC and benefit from:

- fast, convenient online submission

- thorough peer review by experienced researchers in your field

- rapid publication on acceptance

- support for research data, including large and complex data types

- gold Open Access which fosters wider collaboration and increased citations

- maximum visibility for your research: over $100 \mathrm{M}$ website views per year

At BMC, research is always in progress.

Learn more biomedcentral.com/submissions 